\title{
ARBORIZAÇÃO DOS BAIRROS VENEZA E AEROPORTO EM PATO BRANCO - PR
}

\author{
Aquélis Armiliato Emer ${ }^{1}$, Danielle Acco Cadorin², Luana da Silva ${ }^{3}$, \\ Nilvania Aparecida de Mello 4
}

\section{RESUMO}

A arborização urbana é um importante elemento ambiental que mitiga os efeitos negativos que o processo de urbanização intenso e acelerado gera sobre o ambiente. $O$ objetivo desse trabalho foi avaliar a composição da arborização urbana das ruas dos bairros Veneza e Aeroporto na cidade de Pato Branco - PR. Foram identificadas as espécies que apresentavam diâmetro a altura do peito igual ou maior que 0,10 metros, além de terem sido coletadas informações referentes ao tipo de poda e ao tamanho da área livre de pavimentação no entorno das árvores. Foram encontradas 153 árvores no bairro Veneza e 515 no bairro Aeroporto. No bairro Veneza 49,04\% das espécies utilizadas são nativas do bioma local, enquanto no bairro Aeroporto $57,28 \%$ das espécies são exóticas. A maioria dos indivíduos analisados possui canteiro com área livre maior que $1 \mathrm{~m}^{2}$ e não receberam poda na ocasião do levantamento. Dentre as poucas podas observadas, destacam-se as podas drásticas.

Palavras-chave: Espécies exóticas; Área livre; Poda.

Recebido em 16.08.2012 e aceito em 10.05.2015

1 Engenheira Agrônoma, Doutoranda em Fitotecnia, Universidade Federal do Rio Grande do Sul. Departamento de Horticultura e Silvicultura, Porto Alegre, RS, Brasil. aquelis_emer@hotmail.com.

2 Engenheira Agrônoma, Doutoranda em Produção Vegetal, Universidade Estadual do Oeste do Paraná, Centro de Ciências Agrárias, Marechal Cândido Rondon, PR, Brasil. danikadorin@hotmail.com.

3 Engenheira Agrônoma, Doutoranda em Ciência do Solo, Universidade de Santa Catarina Departamento de Solos e Recursos Naturais, Lages SC, Brasil. slv.luana@gmail.com

4 Engenheira Agrônoma, Doutora em Ciência do Solo, Professora do Programa de Pós-Graduação em Desenvolvimento Regional, Universidade Tecnológica Federal do Paraná, Pato Branco, PR, Brasil. nilvania@utfpr.edu.br. 


\section{URBAN FLORESTRY OF NEIGHBORHOODS VENICE AND AIRPORT IN PATO BRANCO - PR}

\section{ABSTRACT}

The urban forestry is an important environmental element which mitigates the negative effects that the process of intense and rapid urbanization has on the environment. The aim of this study was to diagnose the composition of urban forestry of the streets of Veneza and Aeroporto neighborhoods in the city of Pato Branco - PR. Species that had a diameter at breast height equal to or greater than 0.10 meters were identified and it had been collected information regarding the kind of pruning and the size of the free area of paving in the surroundings of trees. There were 153 trees in Veneza neighborhood and 515 in the Aeroporto neighborhood. In Venice neighborhood $49.04 \%$ of the species used are native from the local biome; concerning the Aeroporto neighborhood. $57.28 \%$ of the species are exotic. The most individuals analyzed have free area of paving greater than $1 \mathrm{~m}^{2}$ and received no pruning at the time of the investigation. The drastic pruning stands out among the few observed lopping of trees.

Keywords: Exotic species; Free area; Lopping of trees.

\section{INTRODUÇÃo}

A tendência mundial de concentração da população nas áreas urbanas, aliada a falta de planejamento das cidades tem provocado sérios prejuízos ambientais que se refletem na qualidade de vida da população.

A arborização urbana visa atenuar os impactos causados pelo crescimento das cidades principalmente em relação à redução ou eliminação de cobertura vegetal e da grande impermeabilização dos solos, sendo fundamental na melhoria da qualidade de vida dos moradores citadinos.

A presença de vegetação nas áreas urbanas, conforme Pivetta e Silva Filho (2002) apresenta várias funções importantes, como a melhoria na estética e harmonia do ambiente 
e o bem-estar psicológico para a população. Além disto, a arborização proporciona sombra e diminuição da temperatura, protege e direciona o vento, ameniza a poluição sonora, reduz o impacto da água de chuva e seu escoamento superficial, melhora a qualidade do ar e ainda contribui com a preservação da fauna silvestre. Entretanto, parte desses benefícios são reduzidos em função da falta de planejamento na implantação e manutenção da arborização urbana, da grande utilização de espécies exóticas e da falta de área livre de pavimento para o desenvolvimento arbóreo.

Delespinasse et al. (2011) em levantamento feito sobre a arborização das cidades paranaenses com mais de 60 mil habitantes verificou que das espécies mais utilizadas 75 eram espécies nativas e 78 exóticas. Muitas das espécies comumente utilizadas na arborização das cidades possuem o agravante de serem invasoras, podendo causar danos ambientais.

Conforme a Portaria № 125, de 07 de agosto de 2009, são consideradas espécies exóticas invasoras aquelas introduzidas fora da sua área natural de distribuição cuja entrada ou dispersão ameaça ecossistemas, ambientes, populações, espécies e causa impactos ambientais, econômicos, sociais ou culturais.

Outro fator que diminui os benefícios proporcionados pela arborização urbana e prejudica seu pleno desenvolvimento é a falta de áreas livres de pavimento. Conforme Santos e Teixeira (2001), área livre pode ser definida como o espaço livre de pavimentação que permite a infiltração de água e nutrientes para as árvores. A falta de área livre na arborização urbana pode comprometer o desenvolvimento arbóreo, e ainda, ocasionar danos às calçadas devido à pressão exercida pelo crescimento das raízes.

Gonçalves e Paiva (2006) consideram que quanto maior este espaço, melhor para o crescimento da árvore, contudo, devido a aspectos práticos, o espaçamento de um metro quadrado é considerado ideal.

Mesmo após sua implantação e estabelecimento, as árvores no meio urbano necessitam de tratos culturais que possibilitem a sua condução e sua convivência harmoniosa com os elementos construídos a fim de evitar conflitos e prejuízos ao ambiente urbano. De acordo com o Manual de Normas Técnicas de Arborização Urbana (2007) a poda é a prática mais usada e mais importante no manejo da arborização urbana e é utilizada para facilitar o relacionamento harmonioso das árvores com seu espaço, garantindo a sobrevida do indivíduo adulto e minimizando os efeitos do planejamento inadequado.

Neste contexto, o presente trabalho teve como objetivo diagnosticar a composição da arborização urbana dos bairros Veneza e Aeroporto na cidade de Pato Branco - PR. 


\section{MATERIAIS E MÉTODOS}

O município de Pato Branco está localizado no Sudoeste do Paraná, no terceiro planalto paranaense. O clima do município segundo Köppen é classificado como Cfa - clima subtropical úmido mesotérmico (IAPAR, 2000). A região pertence ao bioma Mata Atlântica e a vegetação original é a Floresta Ombrófila Mista ou Floresta de Araucárias (IBGE, 1992), predominando na região o solo do tipo Latossolo Vermelho Distroférrico. O município encontra-se a $760 \mathrm{~m}$ de altitude, com latitude de $26^{\circ} 13^{\prime} 46^{\prime \prime} \mathrm{S}$ e longitude de $52^{\circ} 40^{\prime} 14^{\prime \prime} \mathrm{W}$ GR. A população total corresponde a 72.260 habitantes (IBGE, 2010), sendo que deste total 94,09\% moram na cidade (IPARDES, 2010).

O Aeroporto é um bairro situado na periferia da cidade, encontrando-se distante do centro e faz divisa com a área rural do município. O bairro apresenta renda média ( $\mathrm{R} \$$ 751,00 a 1250,00) e baixa densidade populacional (18 habitantes/ha) caracterizado por apresentar pouco tráfego e ser basicamente residencial. $O$ bairro Veneza apresenta as mesmas características, contudo apresenta renda média considerada baixa (abaixo de $\mathrm{R} \$$ 350,00 ) e maior densidade populacional (de 27 a 39 habitantes/ha) (IPPUPB, 2006).

A localização dos bairros pode ser verificada na figura 1.

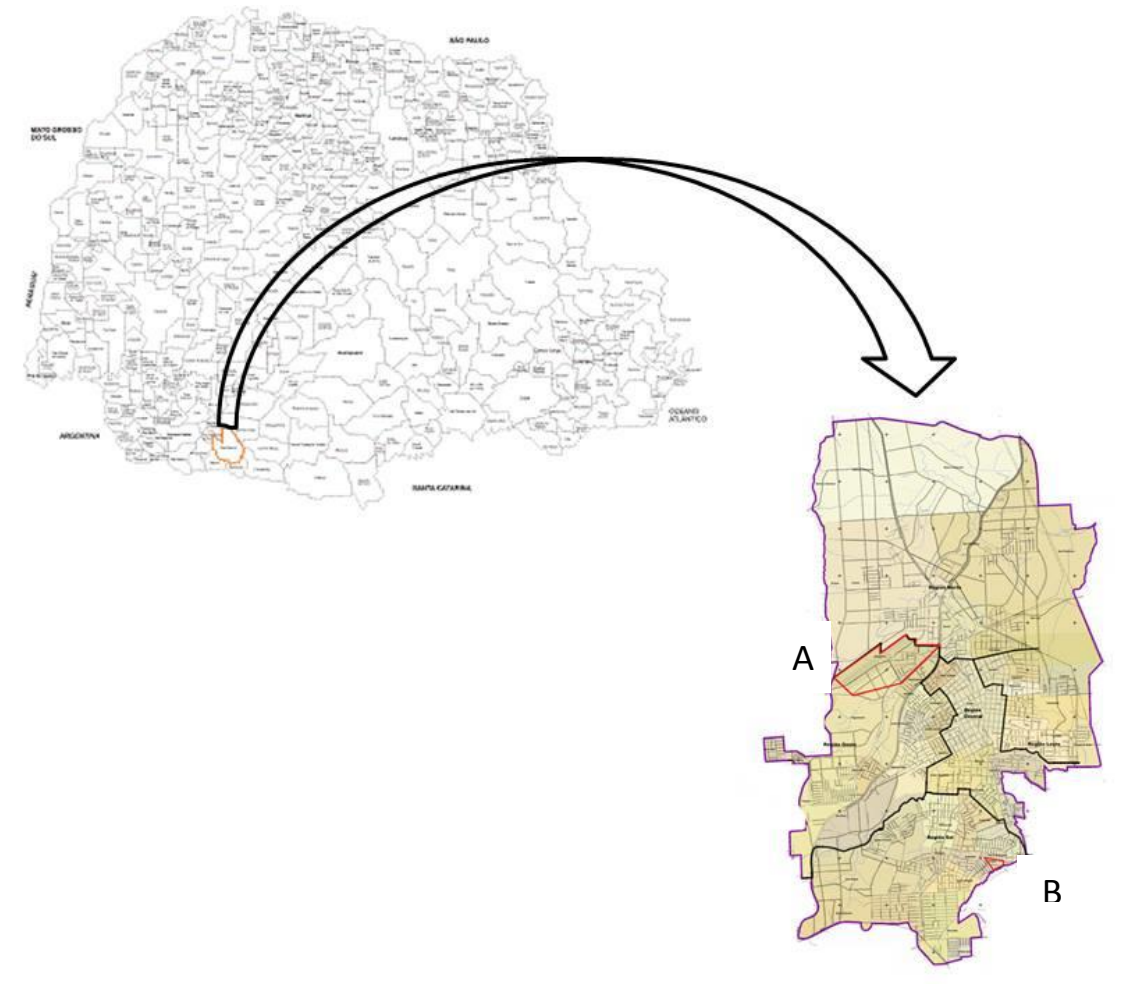

Fonte: Modificado de IPPUB, 2006.

Figura 1. Localização dos bairros Aeroporto (A) e Veneza (B) em Pato Branco, PR, 2012

Figure 1. Location of neighborhoods Aeroporto e Veneza in Pato Branco city, PR, 2012 
Os dados foram coletados no mês de julho de 2012, sendo identificadas todas as árvores presentes nas ruas dos bairros Aeroporto e Veneza, desde que estas apresentassem DAP (diâmetro a altura do peito) igual ou maior de 0,10 metros.

Para localização das vias públicas foi utilizada planta planialtimétrica na escala 1:7.500 para o bairro Aeroporto, e 1:2000 para o bairro Veneza elaborada pelo IPPUPB. As árvores foram identificadas utilizando-se para isso uma planilha para anotação do nome da rua e o nome vulgar de cada espécie. Em caso de dúvida em relação à identificação da espécie foi feita a coleta de material vegetal para posterior identificação em laboratório com auxílio de bibliografia especializada e comparação com exsicatas contidas no herbário da Universidade Tecnológica Federal do Paraná (UTFPR), campus Pato Branco, PR.

Foram feitas a classificação das espécies quanto à origem e avaliações referentes ao tipo de poda e tamanho da área livre.

As espécies foram analisadas quanto à origem, sendo classificadas em Nativas da Floresta Ombrófila Mista (NFO), Nativa do Brasil (NB), Exótica (EX) e Exótica Invasora (EI) conforme Lista Oficial de Espécies Exóticas Invasoras para o Estado do Paraná do ano de 2009 (IAP, 2009).

Os tipos de poda foram classificados em: Poda drástica - quando os galhos foram reduzidos a brotos ou tocos; e outros tipos de poda - que incluíram a poda de formação verificado em mudas, quando o intuito foi de orientar o crescimento da copa - e, poda de manutenção - quando foi utilizada para retirada de galhos para manter a convivência harmoniosa com os demais equipamentos urbanos (CEMIG, 2011). Foram ainda classificados como sem poda os espécimes onde não foram verificados indicativos de cortes recentes.

O tamanho da área livre de pavimentação no entorno das árvores, foi verificado por meio de avaliação direta in locco, sendo considerada boa a área livre quando havia área livre de pavimento igual ou superior a um metro quadrado, pouca área livre quando esta era inferior a um metro quadrado, e sem área livre os locais completamente impermeabilizados.

A frequência de cada espécie foi calculada por meio da razão entre o número de indivíduos da espécie e o número total de indivíduos do bairro.

\section{RESULTADOS E DISCUSSÃO}

Foram identificados 668 indivíduos nos dois bairros analisados, sendo que destes 153 (22,90\%) encontravam-se no bairro Veneza e 515 (77,10\%) no bairro Aeroporto. 
Nos dois bairros analisados a arborização é bastante diversificada em relação à utilização de espécies, contudo pode-se perceber que não houve um planejamento paisagístico, pois na maioria dos casos as espécies foram implantadas ao acaso. Para Santos e Teixeira (2001), embora a escassez de espécies sugira monotonia ao ambiente e possa acarretar na suscetibilidade da arborização aos problemas sanitários, o plantio voluntário, por outro lado, pode levar ao excesso de espécies e gerar composições paisagísticas pouco estéticas.

O bairro Veneza apresenta $39,22 \%$ de sua arborização composta por Schinus molle L. (Aroeira) (Tabela 1), o que não é indicado, pois o predomínio de determinada espécie pode ocasionar maior suscetibilidade a perdas dos espécimes em caso de ataque de pragas e doenças. Dessa forma, a recomendação técnica é de que não sejam utilizadas mais que 15\% de uma mesma espécie na arborização de uma cidade (MILANO; DALCIN, 2000).

Tabela 1. Número de indivíduos, frequência e origem das espécies presentes na arborização do bairro Veneza de Pato Branco - PR, 2012

Table 1. Number of individuals, frequency and origin of species present in the neighborhood urban forestry of Veneza PatoBranco - PR, 2012

\begin{tabular}{|c|c|c|c|c|}
\hline Nome científico & $\begin{array}{l}\text { Nome } \\
\text { Vulgar }\end{array}$ & Origem & Número & Frequência (\%) \\
\hline Bauhinia variegata L. & Pata-de-vaca & EX & 13 & 8,50 \\
\hline Cinnamomum zeylanicum Blume & Falsa -canela & EX & 1 & 0,65 \\
\hline Citrus sp & Citrus & EX & 4 & 2,61 \\
\hline Cupressus spp. & Ciprestre & EX & 3 & 1,97 \\
\hline Eriobotrya japônica Lindl. & Nêspera & $\mathrm{El}$ & 5 & 3,27 \\
\hline Eugenia involucrata DC. & Cereja & NFO & 3 & 1,97 \\
\hline Eugenia uniflora L. & Pitanga & NFO & 6 & 3,92 \\
\hline Grevillea robusta Cunn. & Grevilha & EX & 3 & 1,97 \\
\hline Lagerstroemia indica L. & Extremosa & EX & 12 & 7,84 \\
\hline Ligustrum lucidum Ait. & Ligustro & $\mathrm{El}$ & 11 & 7,17 \\
\hline Michelia champaca L. & Champaca & EX & 1 & 0,65 \\
\hline Morus sp & Amorinha & EX & 1 & 0,65 \\
\hline Não identificadas & $\mathrm{Ni}$ & - & 8 & 5,23 \\
\hline Psidium cattleianum Sabine & Araçá & NFO & 4 & 2,62 \\
\hline Schinus molle L. & Aroeira & NFO & 60 & 39,22 \\
\hline Schinus terebinthifolius Raddi & Aroeira-brava & NFO & 2 & 1,31 \\
\hline $\begin{array}{c}\text { Senna macranthera (Collad.) Irwin \& } \\
\text { Barneby }\end{array}$ & Manduírana & NB & 4 & 2,61 \\
\hline $\begin{array}{c}\text { Senna multijuga (Rich.) H.S Irwin \& } \\
\text { Barneby }\end{array}$ & Aleluia & NFO & 4 & 2,61 \\
\hline $\begin{array}{c}\text { Tabebuia chrysotricha (Mart. ex. DC.) } \\
\text { Standal }\end{array}$ & Ipe-amarelo & NB & 2 & 1,31 \\
\hline Tabebuia heptaphylla (Vell) & Ipe-roxo & NB & 2 & 1,31 \\
\hline Tipuana tipu (Benth.) Kuntze & Tipuana & EX & 4 & 2,61 \\
\hline
\end{tabular}

NFO - Nativa da Floresta Ombrófila Mista (ISERNHAGEN, et al. 2001).NB - Nativa do Brasil (LORENZI, 1992; LORENZI, 1998); E - Exótica BACKES e IRGANG, 2004); EI - Exótica invasora (IAP, 2009). 
A segunda espécie mais observada neste bairro foi a Bauhinia variegata L., (Pata-devaca) representando $8,50 \%$ das espécies, seguidas de Lagerstroemia indica L. (Extremosa) e Ligustrum lucidum Ait (Ligustro) com 7,87 e 7,17\% de frequência no bairro, respectivamente.

O que chama atenção neste bairro é que foram identificadas 21 espécies, 17 delas apresentam frequência inferior a $4 \%$, demonstrando falta de planejamento na utilização dos espécimes.

Admitem-se ter no mínimo de 7 a 10\% frequências para cada espécie utilizada e um número de 10 a 20 espécies para compor a arborização de uma cidade (MILANO E DALCIN, 2000).

No bairro Aeroporto foi verificado que as espécies do gênero Citrus sp representam $29,34 \%$ dos indivíduos identificados no bairro, seguido pela espécie S. molle (aroeira) com 20,58\% (Tabela 2).

A aroeira é uma espécie é nativa do bioma e é utilizada com frequência na arborização da cidade de Pato Branco, sendo citada nos inventários realizados por Silva et al. (2007) no Bairro Centro com 6,3\% de frequência, Silva et al. (2008) com frequência de 7,98\%, 3,65\% e 5,76\% nos bairros Bancários, Brasília e Pinheiros, respectivamente, e ainda no trabalho de Cadorin et al. (2008) que verificou a frequência de 30,98\%, 3,02\% e 5,41\% nos Bairros Cadorin, Parzianello e La Salle, respectivamente. Embora haja uma diferença quantitativa nos resultados a espécie é relatada em todos os bairros analisados na cidade.

A existência de muitos indivíduos com frutos comestíveis pode estar relacionada ao perfil do bairro que é majoritariamente residencial. Foram encontradas as seguintes espécies com frutos comestíveis Eriobotrya japonica Lindl (Nêspera) e Morus sp (Amorinha) que são espécies exóticas, além de frutíferas nativas como Psidium cattleianum Sabine (Araçá), Eugenia involucrata DC (Cereja) e Eugenia uniflora L. (Pitanga) que servem de alimento também para a fauna local, contribuindo para a manutenção da biodiversidade dentro do ambiente urbano.

Nos dois bairros houve um percentual de espécies não identificadas pela falta de folhas ou ramos férteis em virtude da época do ano que foi realizado o inventário e também devido a algumas árvores terem sofrido poda drástica. 
Tabela 2. Número de indivíduos, frequência e origem das espécies presentes na arborização do bairro Aeroporto de Pato Branco - PR, 2012

Table 2. Number of individuals, frequency and origin of species present in the neighborhood urban forestry of Aeroporto PatoBranco - PR, 2012

\begin{tabular}{|c|c|c|c|c|}
\hline Nome científico & $\begin{array}{l}\text { Nome } \\
\text { vulgar }\end{array}$ & Origem & Número & Frequencia (\%) \\
\hline Albizia polycephala (Benth.) Killip & Angico & NFO & 13 & 2,53 \\
\hline Araucaria angustifólia (Bertol.) Kuntze & Araucaria & NFO & 1 & 0,19 \\
\hline Bauhinia variegata $\mathrm{L}$. & $\begin{array}{l}\text { Pata de } \\
\text { vaca }\end{array}$ & EX & 47 & 9,13 \\
\hline Citrus spp. & Citrus & EX & 151 & 29,34 \\
\hline Cupressus spp. & Ciprestre & EX & 1 & 0,19 \\
\hline Eriobotrya japônica Lindl. & Nespera & $\mathrm{El}$ & 8 & 1,55 \\
\hline Eucalyptus sp & Eucalipto & $\mathrm{E}$ & 2 & 0,39 \\
\hline Eugenia involucrata DC. & Cereja & NFO & 3 & 0,58 \\
\hline Eugenia uniflora L. & Pitanga & NFO & 3 & 0,59 \\
\hline $\begin{array}{l}\text { Archontophoenix cunninghamii } \mathrm{H} . \\
\text { Wendl. \& Drude }\end{array}$ & Palmeira & EX & 6 & 1,17 \\
\hline Ficus lyrata Warb. & Ficus & EX & 1 & 0,19 \\
\hline Grevillea robusta Cunn. & Grevilha & EX & 2 & 0,39 \\
\hline Hovenia dulcis Thunberg & Uva japão & $\mathrm{El}$ & 5 & 0,97 \\
\hline Lagerstroemia indica L. & Extremosa & EX & 40 & 7,77 \\
\hline Ligustrum lucidum Ait. & Ligustro & $\mathrm{El}$ & 28 & 5,41 \\
\hline Melia azedarach L. & Cinamomo & El & 8 & 1,55 \\
\hline Morus sp & Amorinha & EX & 2 & 0,39 \\
\hline Não identificadas & $\mathrm{NI}$ & - & 22 & 4,27 \\
\hline Peltophorum dubium (Spreng.) taub. & Canafistula & NFO & 1 & 0,19 \\
\hline Schinus molle L. & Aroeira & NFO & 106 & 20,58 \\
\hline Schinus terebinthifolius Raddi & $\begin{array}{c}\text { Aroeira } \\
\text { brava }\end{array}$ & NFO & 13 & 2,53 \\
\hline $\begin{array}{l}\text { Tabebuia chrysotricha (Mart. ex. DC.) } \\
\text { Standal }\end{array}$ & Ipe amarelo & NB & 5 & 0,97 \\
\hline Tabebuia heptaphylla (Vell) & Ipe roxo & NB & 2 & 0,39 \\
\hline Tibouchina granulosa Cogn. & Quaresmeira & NB & 2 & 0,39 \\
\hline Tipuana tipu (Benth.) Kuntze & Tipuana & EX & 43 & 8,35 \\
\hline \multicolumn{3}{|l|}{ Total de indivíduos } & 515 & 100 \\
\hline
\end{tabular}

NFO - Nativa da Floresta Ombrófila Mista (ISERNHAGEN, et al. 2002). NB -Nativa do Brasil (LORENZI, 1992; LORENZI, 1998); E - Exótica BACKES e IRGANG, 2004); El - Exótica invasora (IAP, 2009).

Das espécies identificadas pode-se verificar que no bairro Veneza quase metade das espécies $(49,04 \%)$ utilizadas para a arborização são nativas da vegetação local (Figura 2). Entretanto, uma parcela considerável $(27,45 \%)$ é de espécies exóticas, sendo que das espécies identificadas no bairro, 10,44\% possuem o agravante de serem espécies consideradas invasoras da Floresta Ombrófila Mista.

No bairro Aeroporto foi verificado que $57,28 \%$ das espécies encontradas no local eram espécies exóticas, 9,52\% exóticas invasoras e apenas 27,18\% das espécies eram nativas da região fitoecológica. 


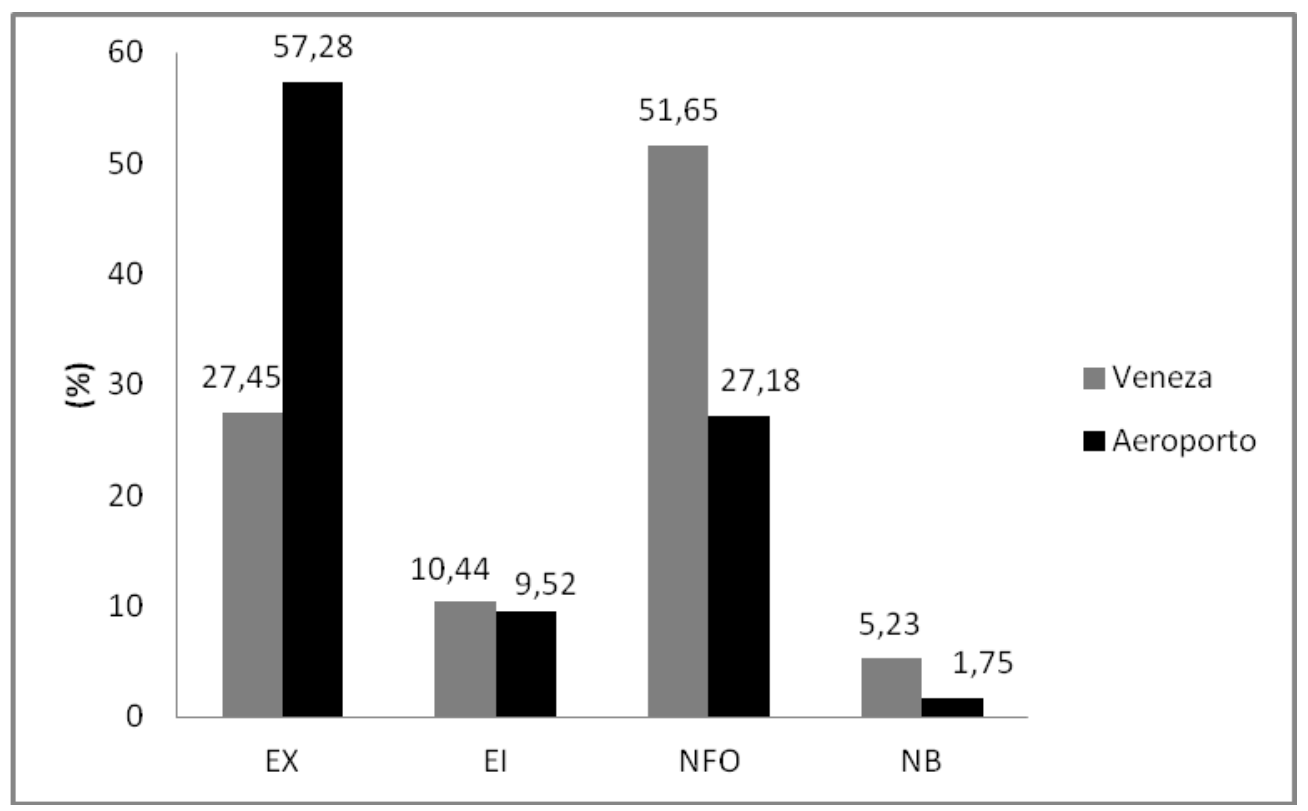

Figura 2. Frequência de espécies exóticas (EX), exóticas invasoras (EI), ativas da Floresta Ombrófila Mista e nativas do Brasil (NB) na arborização dos bairros Veneza e Aeroporto em Pato Branco, PR, 2012

Figure 2. Frequency of exotic species (EX), exotic invasive (EI), the active and native Ombrophilous Mixed Forest of Brasil (NB) in urban forestry of neighborhoods in Veneza and Aeroporto of PatoBranco, PR, 2012

Conforme Ziller (2001) as plantas exóticas invasoras possuem potencial de modificar os sistemas naturais e são a segunda maior ameaça mundial a biodiversidade. Essas espécies, conforme a autora podem competir e ocupar o ambiente das espécies nativas, pois na ausência de fatores limitantes ao seu desenvolvimento como pragas e doenças de sua região de origem, possuem vantagens competitivas em relação as espécies endêmicas.

Sendo assim, deve-se dar preferência a utilização de espécies do bioma local, pois já estão adaptadas ao tipo de solo e clima, além de apresentarem naturalmente maior resistência a pragas e doenças que por ventura podem ficar expostas. Somado a isso, ainda tem-se a possibilidade de mitigar os efeitos que estas espécies possuem para invasão biológica em áreas citadinas e seus entornos.

O bairro Veneza possui uma identidade arbórea mais condizente com as espécies do bioma local, pois $56,88 \%$ das espécies identificadas são nativas da Floresta Ombrófila Mista ou nativas do Brasil, ao contrário do Bairro Aeroporto onde $66,80 \%$ dos espécimes são exóticas.

A principal espécie exótica invasora verificada nos dois bairros é o L. lucidum Ait. (ligustro) com frequência de $7,17 \%$ no bairro Veneza e 5,41\% no bairro Aeroporto. Essa 
frequência pode ser considerada relativamente baixa, visto que em outros bairros avaliados na cidade de Pato Branco, como o Parzianello e o La Salle, 45,75\% e 47,29\%, de sua arborização era composta por esta espécie, respectivamente (CADORIN, 2008). No bairro Centro e Brasília essa porcentagem foi ainda maior sendo que $62,4 \%$ e $70,14 \%$ das árvores encontradas nesses bairros eram de ligustros (SILVA et al., 2007; SILVA et al., 2008).

Segundo Ziller (2001) o gênero Ligustrum está entre as árvores invasoras reconhecidas no Brasil, outras como o Melia azedarach L. (cinamomo) e Hovenia dulcis Thunberg (uva japão) também são citadas pela autora e foram observadas nos bairros analisados. Conforme o Instituto Hórus (2005) a dispersão do ligustro ocorre de forma ornitocórica, sendo que a espécie é conhecida pela grande variedade de habitats que se desenvolvem. Em localidades como Campo Largo - PR, a espécie foi introduzida com fins paisagísticos e de acordo com um levantamento, $60 \%$ da população de uma floresta ciliar no município já é composta pela espécie (Instituto Hórus, 2005).

Nos dois bairros analisados foi constatado que a maioria das árvores se encontrava com boa área livre (Figura 3). Isso ocorreu porque na maioria dos casos as ruas não apresentavam calçadas ou passeio públicos.

Em estudo realizado por Silva et al. (2008) na cidade de Pato Branco-PR, foram verificadas nos bairros Bancários, Brasília e Pinheiros que 41,01\%, 26,46\% e 79,52\% das árvores tinham respectivamente área livre adequada, ou seja, igual ou superior a $1 \mathrm{~m}^{2}$. Cadorin et al. (2008) em pesquisa na mesma cidade constatou que 76,9\%, 65,4 e 46\% das espécies arbóreas dos bairros Cadorin, Parzianello e La Salle tinham boa área livre.

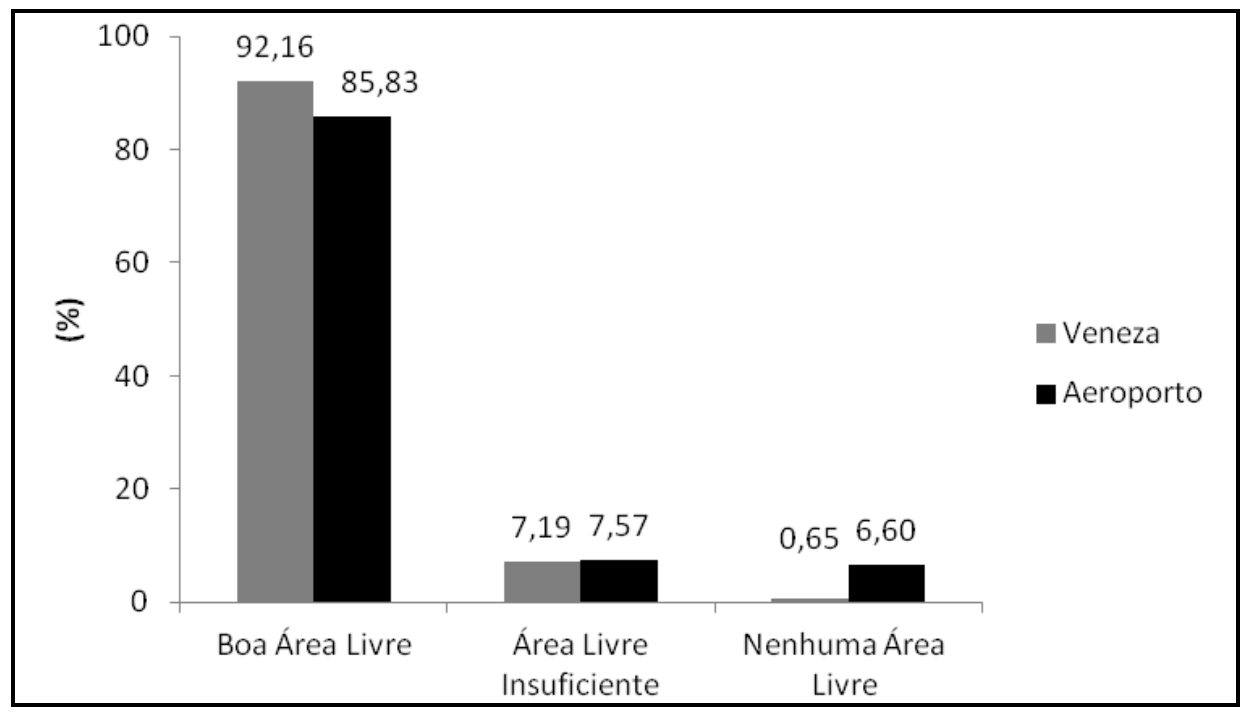

Figura 3. Frequência dos tamanhos de áreas livres dos indivíduos arbóreos dos bairros Veneza e Aeroporto em Pato Branco, PR, 2012

Figure 3. Frequency of the sizes of free areas paving the individual trees of the neighborhoods Veneza and Aeroporto of Pato Branco, PR, 2012 
As altas percentagens de boa área livre nos bairros Aeroporto e Veneza em comparação aos demais bairros avaliados na cidade de Pato Branco, podem estar relacionados ao fato de serem bairros mais periféricos.

A maioria das árvores, considerando os dois bairros, não apresentava qualquer tipo de intervenção. Contudo, pode-se observar que grande parte das podas são drásticas, ou seja, os galhos são reduzidos a brotos, tocos, entrenós ou laterais (CEMIG, 2011). O percentual de podas drásticas chegou a $75 \%$ no bairro Veneza para a espécie Tipuana tipu (tipuana) e a 53,85\% no bairro Aeroporto para a espécie Albizia polycephala (Benth.) Killip (angico) (Tabela 3). Esse percentual é devido à baixa incidência dessas espécies. Outros tipos de poda como a de manutenção foram observadas principalmente para evitar ou diminuir os conflitos com a rede elétrica, além disso, foram verificados alguns tipos de corte de galhos que não configuravam um tipo de poda específico.

Em muitos casos a poda drástica foi executada sem necessidade, pois a árvore não oferecia qualquer intervenção em elementos estruturais como casas ou fiação elétrica. Esse fato também foi observado por Martins et al. (2010) que verificou que entre as árvores em que foi realizada a poda drástica $41,12 \%$ não se encontravam sob a rede elétrica, e portanto, a poda teria sido executada de forma errônea. Santos e Teixeria (2001) argumentaram que podar os exemplares anualmente já se tornou parte da rotina dos moradores no sul do país. Segundo os autores, ao se aproximar o inverno, as árvores são "decapitadas", mesmo que não existam necessidades reais para tal interferência, o que já se tornou um problema cultural, visto que não são todas as espécies que necessitam ou mesmo que aceitam a poda drástica.

Tabela 3. Espécies e tipos de podas executadas nos bairros Veneza e Aeroporto de Pato Branco - PR, 2012

Table 3. Species and types of pruning carried out in the neighbourhoods Veneza and Aeroporto of PatoBranco- PR, 2012

\begin{tabular}{ccccccc}
\hline Nome vulgar & \multicolumn{3}{c}{ Veneza } & \multicolumn{3}{c}{ Aeroporto } \\
\cline { 2 - 7 } & $\begin{array}{c}\text { Poda } \\
\text { drástica (\%) }\end{array}$ & $\begin{array}{c}\text { Outros tipos } \\
\text { de poda (\%) }\end{array}$ & $\begin{array}{c}\text { Sem } \\
\text { poda (\%) }\end{array}$ & $\begin{array}{c}\text { Poda } \\
\text { drástica (\%) }\end{array}$ & $\begin{array}{c}\text { Outros tipos } \\
\text { de poda (\%) }\end{array}$ & $\begin{array}{c}\text { Sem } \\
\text { poda (\%) }\end{array}$ \\
\hline Angico & - & - & - & 53,85 & - & 46,15 \\
Aroeira & 57,65 & 1,67 & 41,66 & 26,41 & 2,83 & 70,76 \\
Extremosa & - & - & 100,00 & 10,00 & - & 90,00 \\
Grevilha & 66,66 & - & 33,34 & - & - & - \\
Ligustro & 45,45 & 18,18 & 36,37 & 17,86 & - & 82,14 \\
Nêspera & - & - & - & 12,50 & - & 87,50 \\
Pata-de-vaca & - & - & 100,00 & 4,25 & - & 95,75 \\
Tipuana & 75,00 & 25,00 & - & 18,60 & - & 87,50 \\
Não & 12,50 & - & 87,50 & 4,54 & - & 95,46 \\
identificadas & & - & & & &
\end{tabular}


A poda drástica não é recomendada, pois conforme a Cemig (2011) esse tipo de intervenção feita sem a técnica apropriada pode causar a formação de ramos frágeis que podem comprometer a estabilidade total ou parcial das árvores. Além disso, podas mal executadas, de alta intensidade e repetidas constantemente podem acelerar a morte da árvore e diminuir a vida útil da planta.

Conforme Martins et al. (2010) podas drásticas devem ser utilizadas somente em casos de extrema necessidade, pelo fato de agredir a integridade da árvore, deixando a planta exposta a agentes externos, provocando a redução ou perda dos seus benefícios estéticos.

Martins et al. (2010) verificaram que indivíduos que sofreram podas mais severas tiveram maiores percentuais de árvores com aspectos fitossanitários negativos, enquanto que árvores sem nenhum tipo de poda tiveram maiores percentuais de árvores sadias.

\section{CONCLUSÕES}

A arborização dos bairros estudados na cidade de Pato Branco, é composta por várias espécies. No bairro Veneza foram encontradas 21 espécies e no Aeroporto 20. Essa diversidade pode ser atribuída ao fato destes bairros serem periféricos e os exemplares arbóreos em sua maioria serem plantados de forma voluntária pelos moradores. Percebe-se que embora seja representativo o número de espécies nativas, poucas são nativas da Floresta Ombrófila Mista, e algumas das espécies utilizadas estão presentes na lista de espécies exóticas invasoras do Estado do Paraná.

A maioria dos indivíduos analisados possui área livre de pavimentação maior que $1 \mathrm{~m}^{2}$, já que em vários locais dos bairros há ausência de calçadas, pois ficam próximos da área rural do município. A maioria das árvores não recebeu poda, mas dentre as podas observadas, destacam-se as podas drásticas, que em muitos casos não foram realizadas com base em necessidades das espécies, ou por ocorrência de conflitos entre a árvore e os elementos urbanos.

\section{REFERÊNCIAS}

BACKES, P.; IRGANG, B. Árvores cultivadas no sul do Brasil: guia de identificação e interesse paisagístico das principais espécies exóticas. Porto Alegre: Palotti, 2004. 204 p. 
CADORIN, D. A. et al. Características da arborização dos Bairros Cadorin, Parzianello e La Salle em Pato Branco - PR (2007). Revista da Sociedade Brasileira de Arborização Urbana, Piracicaba, v.3, n.4, p.40-52, 2008.

CEMIG - Companhia Energética de Minas Gerais. Manual de arborização. Belo Horizonte: Cemig / Fundação Biodiversitas, 2011.112 p.

DELESPINASSE, C. F. B.; HASSE, I.; SILVA, L. M.; CAMPESTRINI, F. Cenário da arborização urbana nas maiores cidades do Estado do Paraná. Revista da Sociedade Brasileira de Arborização Urbana, Piracicaba, v.6, n.3, p.149-171, 2011.

GONÇALVES, W.; PAIVA, H. N. de. Silvicultura urbana: implantação e manejo. Viçosa: Aprenda fácil, 2006. 201 p.

IAP - Instituto Ambiental do Paraná. Lista Oficial de Espécies Exóticas Invasoras para o Estado do Paraná. 2009. Disponível em: <http://www.institutohorus.org.br/ download/marcos_legais/Portaria_IAP_125_2009_Lista_Oficial.pdf> Acesso em: 18 jul., 2012.

IAPAR - Instituto Agronômico do Paraná. Cartas climáticas do Paraná. Londrina: IAPAR, 2000. CD-ROM.

IBGE - Instituto Brasileiro de Geografia e Estatística. Manual técnico da vegetação brasileira. Rio de Janeiro: Fundação Instituto Brasileiro de Geografia e Estatística, Série Manuais Técnicos em Geociências, 1992. 92p.

IBGE - Instituto Brasileiro de Geografia e Estatística. Disponível em: <http://www.censo2010.ibge.gov.br> Acesso em: 18 jul., 2012.

IPPUPB. Instituto de Pesquisa e Planejamento Urbano de Pato Branco - PR. Disponível em: <http://ippupb-org-br.web02.webserverbr.net/default.php.> Acesso em: 23 jul., 2011.

INSTITUTO HÓRUS DE DESENVOLVIMENTO E CONSERVAÇÃO AMBIENTAL. Ligustrum Iucidum. Disponível em: <http://www.institutohorus.org.br/index.php? modulo=inf_ficha_ligustrum_lucidum> Acesso em: 23 jul., 2012.

ISERNHAGEN, I.; SILVA, S. M.; GALVÃO, F. A fitossociologia florestal no Paraná: listagem bibliográfica comentada In: SERNHAGEN, I.; SILVA, S. M.; GALVÃO, F. A fitossociologia florestal no Paraná e os programas de recuperação de áreas degradadas: uma avaliação desenvolvida no Depto. de Botânica da Universidade Federal do Paraná. Curitiba: Departamento de Botânica, 2001. p. 1-175. 
SECRETARIA DE DEFESA DO MEIO AMBIENTE. Manual de Normas Técnicas de Arborização Urbana. Prefeitura Municipal de Piracicaba, 2007. 46 p.

LORENZI, H. Árvores Brasileiras: manual de identificação e cultivo de plantas arbóreas nativas do Brasil. Vol.1, ed. Nova Odessa: Plantarum, 1992. 352 p.

LORENZI, H. Árvores Brasileiras: manual de identificação e cultivo de plantas arbóreas nativas do Brasil. Vol II. 2 ed.Nova Odessa: Plantarum, 1998. 384 p.

MARTINS, L. F. V.; ANDRADE, H. H. B. de; ANGELIS, B. L. D. de; Relação entre podas e aspectos fitossanitários em árvores urbanas na cidade de Luiziana, Paraná. Revista da Sociedade Brasileira de Arborização Urbana, Piracicaba, v.5, n.4, p.141-155, 2010.

MILANO, M. S.; DALCIN, E. C. Arborização de vias públicas. Rio de Janeiro: Light, 2000. 226p.

PIVETTA, K. F. L.; SILVA FILHO, D. F. Arborização Urbana. Boletim Acadêmico. Jaboticabal: UNESP/FCAV/FUNEP, 2002. 74p.

SANTOS, N. R. Z.; TEIXEIRA, I. F. Arborização de Vias Públicas: ambiente X vegetação. Santa Cruz do Sul: Instituto Souza Cruz, 2001. 135p.

SILVA, L. M.; HASSE, I.; MOCCELIN, R.; ZBORALSK, A. R. Arborização de vias públicas e a utilização de espécies exóticas: o caso do Bairro Centro de Pato Branco/PR. Scientia Agraria, Curitiba, v. 8, n. 1, p. 47-53. 2007.

SILVA, L. M.; RODIGHIERO, D. A.; HASSE, I.; CADORIN, D. A. Arborização dos Bairros Pinheiros, Brasília e Bancários em Pato Branco/PR. Scientia Agraria, Curitiba, v.9, n.3, p.275-28. 2008.

ZILLER, S. R. Plantas exóticas invasoras: a ameaça da contaminação biológica. Revista Ciência Hoje, Rio de Janeiro, v. 30 n. 178, p. 77-79. 2001. 